\title{
Energy Cost of Physical Activities and Sedentary Behaviors in Young Children
}

\author{
Anja Großek, Christiana van Loo, Gregory E. Peoples, \\ Markus Hagenbuchner, Rachel Jones, and Dylan P. Cliff
}

\begin{abstract}
Background: This study reports energy expenditure (EE) data for lifestyle and ambulatory activities in young children. Methods: Eleven children aged 3 to 6 years (mean age $=4.8 \pm 0.9 ; 55 \%$ boys) completed 12 semistructured activities including sedentary behaviors (SB), light (LPA), and moderate-to-vigorous physical activities (MVPA) over 2 laboratory visits while wearing a portable metabolic system to measure EE. Results: Mean EE values for SB (TV, reading, tablet and toy play) were between 0.9 to $1.1 \mathrm{kcal} / \mathrm{min}$. Standing art had an energy cost that was 1.5 times that of SB (mean $=1.4 \mathrm{kcal} / \mathrm{min})$, whereas bike riding ( mean $=2.5 \mathrm{kcal} / \mathrm{min}$ ) was similar to LPA (cleaning-up, treasure hunt and walking) (mean $=2.3$ to $2.5 \mathrm{kcal} / \mathrm{min})$, which had EE that were 2.5 times SB. EE for MVPA (running, active games and obstacle course) was 4.2 times SB (mean = 3.8 to $3.9 \mathrm{kcal} /$ min). Conclusion: EE values reported in this study can contribute to the limited available data on the energy cost of lifestyle and ambulatory activities in young children.
\end{abstract}

Keywords: exercise physiology, youth, measurement, health behavior

Several studies have examined young children's energy expenditure (EE) during common sedentary behaviors (SB), light (LPA), and moderate- to vigorous-intensity physical activities (MVPA). ${ }^{1-5}$ However, only a small number of studies have reported EE values for individual activities, which are used in the Compendium of Energy Expenditure for Youth ${ }^{6}$ to provide an estimate of the energy cost of different activities. These values can subsequently be used for a number of purposes, including assigning physical activity intensity categories to parent-reported data. ${ }^{6}$ Reilly et $\mathrm{al}^{3}$ reported EE values calculated from room indirect calorimetry during 3 common SB activities, including TV viewing, sitting playing with toys, and sitting playing at a desk, while Pate et $\mathrm{al}^{1}$ used portable indirect calorimetry and reported EE values for resting, slow walking, brisk walking, and jogging. Adolph et $\mathrm{al}^{2}$ used room indirect calorimetry and also reported EE values for slow walking and jogging among young children but provided additional data for other common activities including SB (movie watching and coloring), standing tasks (playing with toys), and moderate activities (ball play and dance/aerobics). Although room indirect calorimetry has the advantage of not requiring children to wear a face-mask and other equipment to collect respiratory gases, one limitation for simulating free-living ambulatory and MVPA is that space is typically limited. The purpose of this study is to report EE values collected via portable indirect calorimetry for common ambulatory and lifestyle activities in young children.

Großek is with the Institute of Cardiovascular Research and Sports Medicine, German Sport University, Cologne, Germany. Großek, van Loo, Jones, and Cliff (dylanc@uow.edu.au) are with the Early Start Research Institute, School of Education, Faculty of Social Sciences; Peoples is with the Graduate School of Medicine, Faculty of Science Medicine and Health; Hagenbuchner is with the School of Computing and Information Technology, Faculty of Engineering and Information Sciences; University of Wollongong, Australia.

\section{Methods}

\section{Participants}

The study methods have been described in detail elsewhere. ${ }^{7}$ Eleven children ( 5 girls, 6 boys) aged 3 to $6 y$ (mean age $=4.8 \pm$ $0.9 \mathrm{y}$; mean $\mathrm{BMI}=15.9 \pm 1.0 \mathrm{~kg} / \mathrm{m}^{2}$; see Table 1 ) were recruited from the Illawarra region of New South Wales in Australia from April to November 2013. Children were ineligible if they had a disease known to influence their energy balance (for example McArdle's disease), had a physical disability, or asthma, or were claustrophobic. Parent consent was obtained before participation. If desired, parents had the option to attend a familiarization visit, to introduce children to the equipment and procedures. The study was approved by the University of Wollongong Human Research Ethics Committee (HE12/441).

\section{Activities}

Participants completed 12 semistructured activity trials (see Table 2 ) over 2 laboratory visits scheduled within a 3-week period. Participants undertook the following 6 trials at visit 1: watching TV (TV viewing), sitting on floor being read to (reading), standing making a collage on a wall (standing art), walking at a self-selected pace (walking), playing an active game against an instructor (active game), and completing an obstacle course (obstacle course). The remaining 6 trials were completed at visit 2: sitting on a chair playing a computer tablet game (tablet), sitting on floor playing quietly with toys (toy play), treasure hunt (treasure hunt), cleaning-up toys (clean-up), bicycle riding (bike riding), and running at a self-selected pace (running). The duration of each trial was for 4 to $5 \mathrm{~min}$.

\section{Measures and Analyses}

At the first visit children's height and weight was measured to the nearest $0.1 \mathrm{~cm}$ or $0.1 \mathrm{~kg}$ using a portable stadiometer (PE87; 
Table 1 Descriptive Characteristics of Participants

\begin{tabular}{lccc}
\hline & Total & Girls & Boys \\
\hline $\mathrm{N}$ & 11 & 5 & 6 \\
Age $(\mathrm{yr})^{\mathrm{a}}$ & $4.8 \pm 0.8$ & $4.9 \pm 0.5$ & $4.7 \pm 0.9$ \\
Height $(\mathrm{cm})$ & $107.7 \pm 5.3$ & $108.8 \pm 3.4$ & $106.8 \pm 6.0$ \\
Height range $(\mathrm{cm})$ & $100.2-117.7$ & $103.9-113.6$ & $100.2-117.5$ \\
Weight $(\mathrm{kg})$ & $18.5 \pm 2.4$ & $19.2 \pm 2.0$ & $18.0 \pm 2.3$ \\
Weight range $(\mathrm{kg})$ & $15.6-22.7$ & $16.6-22.7$ & $15.6-22.4$ \\
BMI $\left(\mathrm{kg} / \mathrm{m}^{2}\right)$ & $15.9 \pm 1.0$ & $16.2 \pm 1.0$ & $15.7 \pm 0.7$ \\
BMI range $\left(\mathrm{kg} / \mathrm{m}^{2}\right)$ & $14.6-17.6$ & $14.6-17.6$ & $15.0-17.0$ \\
BMI percentile & $59.9 \pm 23.5$ & $68.6 \pm 24.9$ & $52.6 \pm 21.7$ \\
Overweight $(\mathrm{N})^{\mathrm{b}}$ & 3 & 2 & 1 \\
$\mathrm{RMR}^{\mathrm{c}}(\mathrm{ml} / \mathrm{kg} / \mathrm{min})$ & $6.7 \pm 0.6$ & $6.4 \pm 0.4$ & $7.1 \pm 0.5$ \\
$\mathrm{RMR}^{\mathrm{c}}(\mathrm{kcal} / \mathrm{kg} / \mathrm{min})$ & $0.034 \pm 0.003$ & $0.032 \pm 0.002$ & $0.035 \pm 0.003$ \\
\hline
\end{tabular}

Note. Values are Mean $\pm \mathrm{SD}$ unless otherwise stated.

Abbreviations: BMI, body mass index; RMR, resting metabolic rate.

${ }^{a}$ Individual participant ages: 3.2 years, 4.2 years, 4.3 years, 4.4 years, 4.6 years, 4.9 years, 5.1 years, 5.1 years, 5.1 years, 5.4 years, 6.0 years.

${ }^{\mathrm{b}}$ Overweight: $\mathrm{BMI} \geq 85$ th percentile.

c Predicted RMR using Schofield equation. ${ }^{9}$

\section{Table 2 Description of the Activity Trials}

\begin{tabular}{ll}
\hline Activity trial & Description \\
\hline TV viewing & Sit in a comfortable chair watching TV. \\
Tablet activity & Sit in a chair at a table completing a developmentally appropriate puzzle activity on a computer tablet. \\
Reading & Sit on the floor on a cushion and listen to a story-book. \\
Toy play & Sit on the floor playing with toys/blocks/puzzles/dolls. \\
Cleaning-up & Collect toys and equipment and return them to appropriate boxes. \\
Standing art & Create a collage on a whiteboard by sticking art materials onto contact paper. \\
Treasure hunt & Walk through the activity room (20m $\times 10 \mathrm{~m})$ and search for and collect hidden sea creatures. \\
Bike riding & $\begin{array}{l}\text { Ride a bicycle around the activity room (one lap }=45 \mathrm{~m} \text { ), with or without training wheels, as selected by } \\
\text { parent/child. } \\
\text { Move through an obstacle course involving jumping through hoops, crawling through a tunnel, hopping, } \\
\text { climbing up foam stairs and jumping down. }\end{array}$ \\
Active game & $\begin{array}{l}\text { Clean up your backyard-Keep playing area (4m } \times 3 \mathrm{~m} \text { ) "clean" by throwing all bean-bags onto the } \\
\text { instructors playing area. The instructor will do the same. Game ends when playing area is clean (Based on } \\
\text { child's ability, instructor increases/decreases difficulty by playing faster/slower). } \\
\text { Walk with instructor at a self-selected comfortable speed around the marked perimeter of the activity room } \\
\text { (one lap = 45m) } \\
\text { Run with instructor at a self-selected speed around the marked perimeter of the activity room (one lap = } \\
\text { 45m) }\end{array}$ \\
\hline
\end{tabular}

Mentone Educational Centre) and a calibrated electronic scale (Tanita BC; Tanita Corporation of America), respectively. During the activities the MetaMax 3B portable metabolic system (Cortex Biophysical GmbH; Leipzig, Germany) was fitted using a small children's backpack, which was appropriately tightened using adjustable straps. The device and backpack had a total weight of $1.1 \mathrm{~kg}$, making it feasible for use with young children. Following calibration according to manufacturer specifications, oxygen consumption $\left(\mathrm{O}_{2}\right)$ and carbon dioxide production $\left(\mathrm{CO}_{2}\right)$ were measured breath-by-breath using a digital Triple-V-Turbine, an electrochemical cell and an infrared analyzer, respectively. The collected data were stored in onboard memory and later analyzed by MetaSoft (version 4.3.2). Mean $\mathrm{O}_{2}$ consumption and $\mathrm{CO}_{2}$ production for each minute of each activity were converted into units of $\mathrm{EE}$ ( $\mathrm{kcal} / \mathrm{min}$ ) using the Weir equation. ${ }^{8}$ Mean values were calculated from data for the duration of each activity. Children's resting metabolic rate was predicted using Schofield's equation for 3 to 10 years, ${ }^{9}$ to facilitate calculation of Youth-MET values for each activity. ${ }^{10}$ 


\section{Results}

$\mathrm{O}_{2}$ consumption and $\mathrm{EE}$ values for each activity are reported in Table 3. Mean EE values for SB activities including TV, reading, tablet and toy play were between 0.9 and $1.1 \mathrm{kcal} / \mathrm{min}$. Standing art $(1.4 \mathrm{kcal} / \mathrm{min})$ had a mean EE value that was approximately 1.5 times that of TV, which was the SB activity with the lowest EE cost. LPA activities, such as cleaning-up, treasure hunt and walking had EE values ( 2.3 to $2.5 \mathrm{kcal} / \mathrm{min}$ ) that were approximately 2.5 to 2.8 times that of TV. The mean EE cost of bike riding $(2.5 \mathrm{kcal} /$ min) was similar to that of LPA activities. Finally, MVPA activities, including running, active game and obstacle course exhibited EE values ( 3.8 to $3.9 \mathrm{kcal} / \mathrm{min}$ ) that were approximately 4.2 to 4.3 times higher than TV.

\section{Discussion}

This study reported data on the energy cost of SB and physical activities in young children. As expected, SB activities involving sitting such as TV viewing, playing with toys on the floor, and completing an activity on a tablet had the lowest EE values. Standing art, which involved minimal lower body movement and some upper body movement, had an energy cost that was approximately 1.5 times that of the lowest SB. Relative to the lowest SB, there was a 2.5-fold increase in EE for LPA activities such as walking comfortably, cleaning-up toys, and a walking treasure hunt, and a 4-fold increase in EE for MVPA activities, such as running, playing an active game, and completing an obstacle course. The EE of bike riding was more similar to LPA activities than MVPA activities.

Only a small number of studies have reported the energy cost of individual activities in young children. ${ }^{1-3}$ Adolph et $\mathrm{al}^{2}$ used room calorimetry to quantify the energy cost of 7 different activities among 3- to 5-year-olds $(n=64)$. When comparing activities that were similar in both studies, calculated EE was higher in our study, and the difference increased with increasing intensity: TV $(+13 \%)$, tablet/coloring $(+22 \%)$, standing art/ toy play $(+27 \%)$, walk $(+39 \%)$, and run/jogging game $(+63 \%)$. Likewise, Adolph et $\mathrm{al}^{2}$ reported a 2.5-fold increase in EE from SB to MVPA, whereas we found a 4-fold increase. These differences could be due to a number of factors, including differences in measures of $\mathrm{EE}$ and activity protocols (eg, tablet vs coloring, running vs jogging game), and the smaller sample size in our study. Because indirect calorimetry requires children to wear additional equipment, in contrast to room indirect calorimetry as used by Adolph et al, ${ }^{2} \mathrm{EE}$ values in our study might be slightly inflated because children carried the additional weight of the portable metabolic system ( $6 \%$ of their body weight). Likewise, because Adolph et al's ${ }^{2}$ activities were completed in the confined space of a room calorimeter, it is possible that the children in our study were able to reach higher intensities during walking and running around a $45 \mathrm{~m}$ track, potentially contributing to the higher values in our study. Like in our study, Pate et al, ${ }^{1}$ used portable calorimetry among 3 - to 5-year-old children $(n=29)$, and although the $\mathrm{O}_{2}$ consumption values $(\mathrm{ml} / \mathrm{kg} / \mathrm{min})$ in our study were higher, the differences between the studies were generally smaller and more consistent across intensity levels: TV/rest, (13\%), walk (10\%), and run $(14 \%)$. Likewise, Pate et $\mathrm{al}^{1}$ reported a 4 -fold increase in EE from resting to MVPA, which was consistent with our study.

Although the metabolic equivalent of task (MET) value for bike riding in the Compendium of Energy Expenditure for Youth ${ }^{2}$ (light effort $=4.7$ METs, moderate effort $=6.2$ METs) is more similar to MVPA activities (eg, walk, hard effort = 3.6 METS, run, light effort $=7.7$. METs) rather than LPA activities (eg, walk, light effort $=2.9$ METs $),{ }^{6}$ in this study the EE value was more similar to walking at a comfortable pace and other LPA activities, rather than MVPA activities. EE values for bike riding may have been lower than expected because the activity was completed in an indoor environment where space was more restricted compared with outdoor environments. Likewise, the values for bike riding may have been lower because some participants were in the process of learning this skill, as indicated by their use of training wheels. Furthermore, as muscle mass is a key determinant of oxygen consumption, less muscle mass can be needed using training wheels, as the torso and upper body are not used.

A significant strength of this study was the collection of individual $\mathrm{EE}$ values for a wide range of common activities for young children that elicited a 4-fold change in their EE, from SB to MVPA. Some limitations, however, should also be considered when interpreting the results. Although portable indirect calorimetry requires children to were a face-mask and be fitted with equipment that may influence how activities are completed, this method collects breath-by-breath data and thus avoids a lag in EE values that may be possible when using indirect room calorimetry. The modest number of participants might influence the generalizability of our

Table 3 Oxygen Consumption and Energy Expenditure for Each Activity

\begin{tabular}{lcccccc}
\hline Activity & $\mathrm{ml} / \mathbf{k g} / \mathbf{m i n}$ & Range & L/min & Range & kcal/min & Range \\
\hline TV viewing & $10.3 \pm 2.43$ & $6.7-14.3$ & $0.2 \pm 0.04$ & $0.1-0.3$ & $0.9 \pm 0.29$ & $0.2-1.3$ \\
Reading & $11.7 \pm 2.35$ & $7.9-15.6$ & $0.2 \pm 0.04$ & $0.1-0.3$ & $0.9 \pm 0.30$ & $0.2-1.4$ \\
Tablet Activity & $12.1 \pm 1.64$ & $9.7-14.4$ & $0.2 \pm 0.03$ & $0.2-0.3$ & $1.1 \pm 0.16$ & $0.8-1.4$ \\
Toy play & $14.8 \pm 2.73$ & $10.8-19.5$ & $0.3 \pm 0.05$ & $0.2-0.4$ & $1.3 \pm 0.22$ & $0.9-1.7$ \\
Standing Art & $15.9 \pm 3.00$ & $11.2-20.5$ & $0.3 \pm 0.06$ & $0.2-0.4$ & $1.4 \pm 0.28$ & $1.0-1.8$ \\
Cleaning-up & $25.2 \pm 5.07$ & $16.1-36.3$ & $0.5 \pm 0.08$ & $0.3-0.6$ & $2.3 \pm 0.35$ & $1.6-2.9$ \\
Treasure hunt & $26.8 \pm 3.29$ & $20.7-33$ & $0.5 \pm 0.10$ & $0.3-0.7$ & $2.4 \pm 0.43$ & $1.7-3.4$ \\
Bike riding & $27.9 \pm 6.70$ & $18.5-43.6$ & $0.5 \pm 0.14$ & $0.3-0.7$ & $2.5 \pm 0.63$ & $1.4-3.6$ \\
Walking & $28.0 \pm 3.90$ & $23.3-34.8$ & $0.5 \pm 0.10$ & $0.4-0.8$ & $2.5 \pm 0.48$ & $1.8-3.5$ \\
Running & $42.6 \pm 7.39$ & $29.6-54.6$ & $0.8 \pm 0.13$ & $0.6-1.0$ & $3.9 \pm 0.61$ & $3.1-5.0$ \\
Obstacle course & $43.3 \pm 6.73$ & $28.3-51.6$ & $0.8 \pm 0.13$ & $0.7-1.0$ & $3.9 \pm 0.64$ & $3.1-5.1$ \\
Active game & $41.7 \pm 6.51$ & $28.6-50.9$ & $0.8 \pm 0.13$ & $0.6-0.9$ & $3.8 \pm 0.66$ & $2.6-4.5$ \\
\hline
\end{tabular}


findings, as other studies have examined EE among 30 to 60 young children. ${ }^{1,2}$ Likewise, although the LPA and MVPA activities were completed at self-selected intensities, trials were semistructured and completed in an indoor exercise laboratory environment which might impact their ability to reflect free-living behaviors. This study demonstrates that collecting EE data in young children during a variety of ambulatory and lifestyle activities is feasible. Future studies among larger samples of young children, using portable indirect calorimetry during simulated free-living activities that could be completed outside of exercise laboratories would provide useful information to compare against the values reported in this study. In the interim, the EE values reported in this study can contribute to the limited available data on the energy cost of lifestyle and ambulatory activities in young children.

\section{Acknowledgments}

We thank the participants and their parents, and Melinda Smith for her assistance with recruitment and implementation of the activity protocol.

\section{References}

1. Pate RR, Almeida MJ, McIver KL, Pfeiffer KA, Dowda M. Validation and calibration of an accelerometer in preschool children. Obesity (Silver Spring). 2006;14(11):2000-2006. PubMed doi:10.1038/ oby.2006.234

2. Adolph AL, Puyau MR, Vohra FA, Nicklas TA, Zakeri IF, Butte NF. Validation of uniaxial and triaxial accelerometers for the assessment of physical activity in preschool children. J Phys Act Health. 2012;9(7):944-953. PubMed
3. Reilly JJ, Janssen X, Cliff DP, Okely AD. Appropriateness of the definition of 'sedentary' in young children: Whole-room calorimetry study. J Sci Med Sport. 2015;18(5):565-568. PubMed doi:10.1016/j. jsams.2014.07.013

4. Butte NF, Wong WW, Lee JS, Adolph AL, Puyau MR, Zakeri IF. Prediction of energy expenditure and physical activity in preschoolers. Med Sci Sports Exerc. 2014;46(6):1216-1226. PubMed doi:10.1249/ MSS.0000000000000209

5. Janssen X, Cliff DP, Reilly JJ, et al. Predictive validity and classification accuracy of ActiGraph energy expenditure equations and cut-points in young children. PLoS One. 2013;8(11):e79124. PubMed doi:10.1371/journal.pone.0079124

6. Ridley K, Ainsworth BE, Olds TS. Development of a compendium of energy expenditures for youth. Int J Behav Nutr Phys Act. 2008;5:45. PubMed doi:10.1186/1479-5868-5-45

7. Hagenbuchner M, Cliff DP, Trost SG, van Tuc N, Peoples GE. Prediction of activity type in preschool children using machine learning techniques. J Sci Med Sport. 2015;18(4):426-431. PubMed doi:10.1016/j. jsams.2014.06.003

8. Weir J. New methods for calculating metabolic rate with special reference to protein metabolism. J Physiol. 1949;109(1-2):1-9. PubMed doi:10.1113/jphysiol.1949.sp004363

9. Schofield WN. Predicting basal metabolic rate, new standards and review of previous work. Hum Nutr Clin Nutr. 1985;39(Suppl 1):5-41. PubMed

10. McMurray RG, Butte NF, Crouter SE, et al. Exploring metrics to express energy expenditure of physical activity in youth. PLOS ONE. 2015;10(6):e0130869. 